\title{
Prevalence of mutations associated with antimalarial drugs in Plasmodium falciparum isolates prior to the introduction of sulphadoxine-pyrimethamine as first-line treatment in Iran Sedigheh Zakeri*1, Mandana Afsharpad ${ }^{1}$, Ahmad Raeisi ${ }^{2}$ and Navid Dinparast Djadid ${ }^{1}$
}

Address: ${ }^{1}$ Malaria and Vector Research Group (MVRG), Biotechnology Research Center, Institut Pasteur of Iran, Pasteur Avenue, P.O.BOX 1316943551, Tehran, Iran and ${ }^{2}$ Center for Diseases Management and Control, Tehran, Iran

Email: Sedigheh Zakeri* - zakeris@yahoo.com; Mandana Afsharpad - afsharpad@yahoo.com; Ahmad Raeisi - ahmadraeisi@yahoo.com; Navid Dinparast Djadid - navid@pasteur.ac.ir

* Corresponding author

Published: 13 November 2007

Malaria Journal 2007, 6: I48 doi:10.1 I86/1475-2875-6-148
Received: 26 June 2007

Accepted: I3 November 2007

This article is available from: http://www.malariajournal.com/content/6/I//48

(C) 2007 Zakeri et al; licensee BioMed Central Ltd.

This is an Open Access article distributed under the terms of the Creative Commons Attribution License (http://creativecommons.org/licenses/by/2.0), which permits unrestricted use, distribution, and reproduction in any medium, provided the original work is properly cited.

\begin{abstract}
Background: This work was carried out to assess the patterns and prevalence of resistance to chloroquine (CQ) and sulphadoxine-pyrimethamine (SP) in Iran.

Methods: The prevalence of pfcrt K76T, pfmdr I N86Y, pfdhfr N5II, C59R, SI08N/T and II64L and codons S436F/A, A437G, K540E, A58IE, and A6I3S/T in pfdhps genes were genotyped by PCR/ RFLP methods in 206 Plasmodium falciparum isolates from Chabahar and Sarbaz districts in Sistan and Baluchistan province, Iran, during 2003-2005.
\end{abstract}

Results: All P. falciparum isolates carried the $108 \mathrm{~N}$, while $98.5 \%$ parasite isolates carried the $59 \mathrm{R}$ mutation. $98.5 \%$ of patients carried both $108 \mathrm{~N}$ and $59 \mathrm{R}$. The prevalence of pfdhps $437 \mathrm{G}$ mutation was 17\% (Chabahar) and 33\% (Sarbaz) isolates. 20.4\% of samples presented the pfdhfr 108N, 59R with pfdhps 437G mutations. The frequency of allele pfort 76T was $98 \%$, while $41.4 \%$ (Chabahar) and $27.7 \%$ (Sarbaz) isolates carried pfmdrl 86Y allele. Eight distinct haplotypes were identified in all 206 samples, while the most prevalent haplotype was $\mathbf{T}_{76 /} \mathrm{N}_{86 /} \mathrm{N}_{51} \mathbf{R}_{59} \mathbf{N}_{108 /} \mathrm{A}_{437}$ among both study areas.

Conclusion: Finding the fixed level of $\mathrm{CQ}$ resistance polymorphisms (pfort 76T) suggests that $\mathrm{CQ}$ must be withdrawn from the current treatment strategy in Iran, while SP may remain the treatment of choice for uncomplicated malaria.

\section{Background}

Drug resistance is the most serious problem in achieving control of malaria. The spread of Plasmodium falciparum resistance to available cheap drugs, the increased cost of insecticides, the vector's resistance to insecticides and the lack of an effective vaccine, together with a socio-eco- nomic instability in many malaria-endemic region, impact on malaria control. Therefore, surveillance and prevention of drug resistance and also effective curative chemotherapy have become more important to be considered as the primary approach to malaria control. For decades, chloroquine (CQ) was an efficacious antimalarial, 
however malaria parasite resistance to treatment with chloroquine has already complicated malaria management and has been associated with increased malaria morbidity and mortality $[1,2]$. The antimalarial compounds sulphadoxine $(\mathrm{S})$ and pyrimethamine $(\mathrm{P})$ are usually given together as a synergistic combination, known commercially as Fansidar ${ }^{\circledR}[3]$, and represent an effective agent against chloroquine-resistant $P$. falciparum. However, resistance to this drug has also been reported from parts of South East Asia, Latin America and Africa [4-6].

In Iran, malaria was a serious health problem in the past and according to the records of Center for Diseases Management and Control (CDMC), Ministry of Health and Medical Education (MHME), during the last decade (1990-1999) the annual malaria cases have decreased from 96,340 in 1991 to 24,000 in 2005. Malaria transmission mostly occurs in the south-eastern parts of the country in Sistan-Baluchistan, Hormozgan and Kerman (mainly in Kahnoudj) provinces. Resistance of $P$. falciparum to chloroquine has increased since it was first reported in 1983 in Sistan-Baluchiatan province and later in Hormozgan province in 1986 [7], and currently accounts for more than $78.5 \%$ of treatment failures in south-eastern provinces of Iran [8]. Resistance to SP was confirmed in malaria-endemic areas of Iran by in vitro and in vivo tests [9]. Despite the report of resistance to these drugs in Iran, CQ and SP are still used as antimalarial drugs in this region.

Plasmodium falciparum resistance to CQ and SP has been associated with combinations of the presence of single nucleotide polymorphisms (SNPs) in a number of $P$. falciparum genes. CQ resistance is associated with polymorphisms in the $P$. falciparum chloroquine resistance transporter ( $p f c r t$ ) gene [10-12], while polymorphisms in the $P$. falciparum multidrug resistance 1 ( $p f m d r 1$ ) gene have been shown by transfection to modulate higher levels of CQ resistance [13]. In this regards, K76T mutation of the $p f c r t$ gene is strongly associated with CQ resistance [10], while N86Y mutation of $p f m d r 1$ gene may modulate its degree [14]. SP resistance is associated with polymorphisms in the dihydropteroate synthetase gene (dhps) and the didydropolate reductase gene $(d h f r)[15,16]$. Among SNPs currently identified, the N51I, C59R, I164L with $\mathrm{S} 108 \mathrm{~N} / \mathrm{T}$ in $\mathrm{dhfr}$ confer increasing levels of pyrimethamine resistance [17]. Similarly, polymorphisms at positions S436A/F, A437G, L540E, A581G and S613A/T in $d h p s$ are the key mutations associated with sulphadoxine resistance. The polymorphism $437 \mathrm{G}$ in $d h p s$ gene appears to be selected first by drug pressure and accompany with polymorphisms at other positions confers increasing levels of resistance to this drug [18]. Several studies have revealed that the differing degrees of antimalarial drug resistance are dependent upon the number and combina- tion of mutations present in aforementioned genes [1921]. Initial clinical failures to SP usually become evident when an isolate carries a triple mutant, 51I, 59R and 108N in the $p f d h f r$ gene with or without additional mutations in pfdhps [22-24], however, the quintuple mutant carrying all of $d h f r$ triple mutant at codons 51I, 59R and $108 \mathrm{~N}$ also in combination with double mutant at codons $437 \mathrm{G}$ and $540 \mathrm{E}$ in $d h p s$ are associated with SP treatment failure [20,24-27]. These SNPs could be used as rapid molecular marker for detecting these mutations, therefore represent molecular epidemiology surveillance tools of antimalarial resistance, which may replace the conventional in vitro or in vivo phenotyping assays $[28,29]$.

The aim of the present study was to complement existing data on molecular studies by determining the frequency of known mutations in $d h f r$ and $d h p s$ genes of $P$. falciparum isolates from south-eastern region of Iran. In addition, we investigated the possibility of an association between CQ and SP resistance by analysing $p f c r t$ and $p f m d r 1$ mutations on the same $P$. falciparum isolates. The data presented here revealed the prevalence of mutations associated to CQ and SP resistance in P. falciparum isolates collected at health centers in Chabahar and Sarbaz districts in Sistan and Baluchistan province, Iran and therefore, will be contributed to the development of strategies for therapeutic intervention of malaria in Iran.

\section{Materials and methods}

\section{Study sites and samples collection}

Chabahar and Sarbaz districts in Sistan and Baluchistan province in south-eastern part of Iran have been selected as study areas. Both areas are malaria endemic and the patients have access to antimalarial drugs through local health centers. In Chabahar district samples were collected from Chabahar, Nowbandiyan and Dargas health centers, however, in Sarbaz district most of the samples were collected from Pishin health center $(5 \mathrm{Km}$ far from border line with Pakistan), where, there is a lot of population movement to Pakistan and vice versa (Figure 1). In these regions, malaria transmission is year-round with two peaks, the first in May to August with P. vivax as the predominant species and the second peak from October to November, when both $P$. falciparum and $P$. vivax infections are generally equally recorded. 206 blood samples were collected from $P$. falciparum-infected patients, aged from 1 to $>60$ years old with Iranian, Afghani and Pakistani nationals from Chabahar $(\mathrm{n}=152)$ and Sarbaz $(\mathrm{n}=$ 54) districts in Sistan and Baluchistan during 2003 to October 2005.

Thin and thick blood films were stained with Giemsa and examined microscopically for detection of $P$. falciparum parasite. Approximately $1 \mathrm{ml}$ venous blood was obtained in tube containing EDTA from patients who were con- 


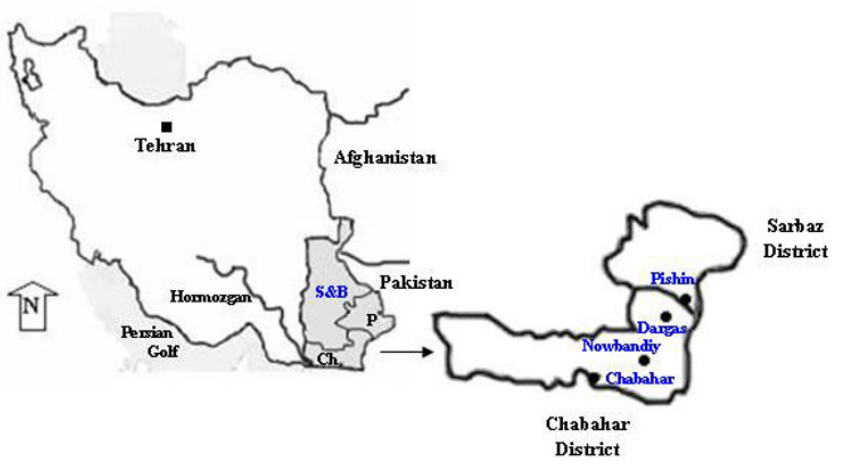

Figure I

Map of Iran indicating the location of the study area in Chabahar and Sarbaz districts situated in the south-eastern corner of Baluchistan Province, from where the $P$. falciparum isolates were collected. S\&B: Sistan and Baluchistan province, Ch: Chabahar, P: Pishin

firmed to be positive for the presence of $P$. falciparum parasites. Then all patients were treated with CQ $(25 \mathrm{mg} / \mathrm{kg}$ body weight over 3 days) plus primaquine $(P)(0.75 \mathrm{mg} /$ $\mathrm{kg}$ single dose in third day) as first line drug and if needed treated with single dose of SP as second line drug for treatment of uncomplicated malaria cases. Patients' or parents' informed consent was obtained before inclusion in the study. The study was reviewed by, and received Ethical Clearance from Pasteur Institute of Iran. Blood samples were collected in tube containing EDTA, stored at $4^{\circ} \mathrm{C}$, and then transported to the main laboratory in Tehran.

\section{Parasite DNA extraction and nested polymerase chain reaction amplification of pfdhfr and pfdhps genes}

The Parasite genomic DNA was extracted from infected red blood cells using phenol/phenol-chloroform followed by ethanol precipitation as described previously [30]. Nested PCRs were performed for $d h f r$ and $d h p s$ genes, and all reactions were carried out in $25 \mu \mathrm{l}$ reaction mixtures containing 1.5-3 $\mathrm{mM} \mathrm{MgCl}_{2}, 200 \mu \mathrm{M}$ dNTP mixture (invitrogene, USA), 1 unit of Taq polymerase (invitrogen, USA), and a pair of primers (10 pmol each). For both $d h f r$ and $d h p s$ one to two microliters of DNA was used as template in the first reaction and for second reaction, $1 \mu \mathrm{l}$ of first PCR product, if no band was seen from first round PCR product, whereas $1 \mu \mathrm{l}$ of a 1/100 dilution of the samples with an intense band was used as template for secondary PCR. The negative (water) controls were used in all PCRs. The PCR primers and conditions for both genes were those published by Duraisingh et al. [31]. Secondary PCR products were resolved by electrophoresis on $1-2 \%$ agarose gels and visualized by staining with ethidium bromide.

\section{Restriction Fragment Length Polymorphism-Polymerase Chain Reaction of pfdhfr and pfdhps genes}

The mutation specific restriction endonuclease digestion was used to detect SNPs in $d h f r$ at positions N51I, C59R, $\mathrm{S} 108 \mathrm{~N} / \mathrm{T}, \mathrm{I} 164 \mathrm{~L}$, and in $\operatorname{dhps}$ at position S436F/A, A437G, K540E, A581E, A613S/T [31]. A number of restriction enzymes were used for RFLP of PCR products. For $d h f r$, the PCR products were digested with TasI and TaqI to determine the polymorphisms at codons 51 and 59, respectively. Three enzymes, AluI, BsrI, and MvaI were used to identify wild and mutant $d h f r$ allele at codon 108 and DraI used to detect mutation at position I164L. For dhps, the PCR products were digested with HhaI, MnlI and HindIII to determine the polymorphisms at codon 436, AvaII and MwoI for codon 437, FokI, BstUI and MwoI to determine the polymorphisms at codons 540, 580 and 613, respectively. Digestions were done in $20 \mu \mathrm{l}$ reactions containing $10 \mu \mathrm{l}$ of PCR fragments according to the manufacturer's instructions (New England Biolab, Beverly, MA, USA; Roche, Germany; Invitrogen, Carlsbad, CA). Digested products were subjected to electrophoresis on $1.5-2 \%$ agarose or $2-3 \%$ Metaphor agarose gels, and visualized by ultraviolate (UV) transillumination.

\section{Detection of pfcrt and pfmdr I mutations by restriction digestion of PCR products}

For mutation detection at codon K76T in pfcrt and N86Y in $p f m d r 1$ genes one to two microliters of DNA was used as template in the first reaction (if no band was seen), whereas $1 \mu$ l of a $1 / 100$ to $1 / 500$ dilution of the samples with an intense band from first round PCR product was used as template for the secondary PCR. The PCR primers and conditions for both genes were those published previously $[10,32]$. Purified genomic DNA from $P$. falciparum clones HB3 (Chloroquine sensitive) and Dd2 (chloroquine resistant) were used as positive controls, and water, extracted uninfected blood used as negative controls. PCR products were resolved by electrophoresis on 1-2\% agarose gels and visualized by staining with ethidium bromide.

Following amplification of the fragments concerned, polymorphisms in the $p f c r t$ and $p f m d r 1$ genes were assessed by the mutation specific restriction endonuclease digestion to detect Single Nucleotide Polymorphisms (SNPs) in pfcrt at positions K76T, and in pfmdr1 at position N86Y/ $\mathrm{H}[10,32]$. A number of restriction enzymes were used for RFLP of PCR products. For $p f c r t$, the PCR products were digested with ApoI, determine the polymorphisms at codons 76. For pfmdr1, three enzymes, ApoI, NsiI and AFlIII were used to identify polymorphisms at codon 86 . Digestions were done in $20 \mu \mathrm{l}$ reactions containing $10 \mu \mathrm{l}$ of PCR products according to the manufacturer's instructions (New England Biolab, Beverly, MA, USA; and/or Fermentase, Vilnius, Lithuania; New England Biolabs, 
Beverly, MA). If there was doubt about a complete digestion, reactions were repeated overnight. Digested products were subjected to electrophoresis on $1.5-2 \%$ agarose or $2-3 \%$ Metaphor agarose gels, and visualized by ultraviolate (UV) transillumination.

\section{Results \\ Pfdhfr and pfdhps genotypes}

All 206 P. falciparum isolates were successfully genotyped for the detection of $d h f r$ and $d h p s$ mutations associated to SP resistance. All P. falciparum isolates (100\%) from both Chabahar and Sarbaz districts were found to carry the mutant type $108 \mathrm{~N}$, and $98.5 \%$ of them carried the $59 \mathrm{R}$ mutation, however the 51I mutation was present in $0.97 \%$ of examined samples (Table 1 ). The majority of the Patients $(98.5 \%)$ were found to carry both $108 \mathrm{~N}$ and $59 \mathrm{R}$ in pure form, while retaining a wild-type mutation at position 51 and 164 (Table 2).

In case of the dhps gene, polymorphisms in different loci of dhps (S436F/A, A437G, K540E, A581E and A613S/T)) were investigated. All isolates were found to carry wildtype amino acids at positions 436, 540, 581, and 613, while 437G mutation in pur form was detected among $17 \%$ and $33 \%$ examined samples collected from Chabahar and Sarbaze districts, respectively (Table 1). Mutations at codons $108 \mathrm{~N}$, 59R of pfdhfr with pfdhps 437G were detected in $20.4 \%$ of examined samples (Table 2 ).

\section{pfcrt K76T and pfmdr I N86Y}

The frequency of pure mutant of allele $p f c r t 76 \mathrm{~T}$ was $98 \%$ in both Chabahar and Sarbaz districts (Table 1). The fre- quency of the mutant $p f m d r 186 \mathrm{Y}$ allele was $41.4 \%$ and $27.7 \%$ among isolates from Chabahar and Sarbaz districts, respectively (Table 1 ).

\section{Distribution of pfcrt, pfmdrl, pfdhfr and pfdhps haplotypes in Iran}

Combination of $p f c r t, p f m d r 1$, $p f d h f r$ and $p f d h p s$ haplotypes among all 206 samples in this study demonstrated 8 distinct haplotypes (Figure 2). The two most prevalent haplotypes among samples were $\underline{\mathbf{T}}_{76 /} \mathrm{N}_{86} \mathrm{~N}_{51} \underline{\mathbf{R}}_{59} \underline{\mathbf{N}}_{108 /} \mathrm{A}_{437}$ (47\%) and $\underline{\mathbf{T}}_{76} \underline{\mathbf{Y}}_{86 /} \mathbf{N}_{51} \underline{\mathbf{R}}_{59} \underline{\mathbf{N}}_{108 /} \mathrm{A}_{437}(28.6 \%)$. In addition, the majority of isolates from Chabahar $(48 \%)$ and Sarbaz (43\%) were belonging to haplotype $\underline{\mathbf{T}}_{76} / \mathrm{N}_{86} / \mathrm{N}_{51} \underline{\mathbf{R}}_{59} \underline{\mathbf{N}}_{108} /$ $\mathrm{A}_{437}$ (Figure 2). pfcrt 76T and pfmdr1 86Y with the pfdhfr $59 \mathrm{R}, 108 \mathrm{~N}$ and $p f d h p s$ 437G mutations was detected in $10.7 \%$ isolates from Chabahar $(\mathrm{n}=13)$ and Sarbaz $(\mathrm{n}=9)$ districts (Table 2).

\section{Discussion}

In Iran, chloroquine-resistant parasites were first observed in 1983 [33] and later reported for more than $78.5 \%$ of treatment failures in south-eastern provinces of Iran [8], but it is still under use as antimalarial drugs in these regions. In both Chabahar and Sarbaz districts pfcrt 76T polymorphism was fixed in parasites populations, as shown by the high rate of polymorphism and no mixed alleles, however, lower frequency of $p f m d r 186 \mathrm{Y}$ polymorphism has been detected among Sarbaz isolates. Based on the prevalence of $p f c r t 76 \mathrm{~T}(98 \%)$ and $p f m d r 1$ 86Y $(37.8 \%)$ in all 206 isolates, it could be concluded that pfcrt76T but not pfmdr1 86Y mutation is strongly associ-

Table I: Frequency distribution of mutations conferring resistance to chloroquine and pyrimethamine-sulphadoxine in Plasmodium falciparum isolates from southeastern Iran

\begin{tabular}{|c|c|c|c|c|}
\hline & Gene & Codon & Chabahar $(n=152)$ & Sarbaz $(n=54)$ \\
\hline & & & Mutation (\%) & Mutation (\%) \\
\hline \multirow[t]{3}{*}{ Choloroquine } & pfcrt & 76T & 149 (98\%) & $53(98 \%)$ \\
\hline & pfmdr I & $86 Y$ & $63(41.4 \%)$ & 15 (27.7\%) \\
\hline & & $86 N / Y$ & $\mathrm{I}(0.77 \%)$ & $\mathrm{I}(\mathrm{I} .96 \%)$ \\
\hline \multirow[t]{5}{*}{ Pyrimethamine } & pfdhfr & 511 & I (0.77\%) & I (1.96\%) \\
\hline & & $59 R$ & $150(98.6 \%)$ & $53(98 \%)$ \\
\hline & & $108 N$ & $152(100 \%)$ & $54(100 \%)$ \\
\hline & & $108 T$ & - & - \\
\hline & & 164L & - & - \\
\hline \multirow[t]{7}{*}{ Sulphadoxine } & pfdhps & 436A & - & - \\
\hline & & $436 \mathrm{~F}$ & - & - \\
\hline & & 437G & $26(17 \%)$ & $18(33 \%)$ \\
\hline & & 437A/G & $3(1.9 \%)$ & $3(5.5 \%)$ \\
\hline & & $540 \mathrm{E}$ & - & - \\
\hline & & $58 \mid G$ & - & - \\
\hline & & $613 N$ & - & - \\
\hline
\end{tabular}


Table 2: The frequency distribution of SNPs combinations of $p f c r t$ and $p f m d r l$ associated to chloroquine resistance, plus $p f d h f r$ and pfdhps alleles associated with pyrimethamine-sulphadoxine resistance in clinical isolates of Plasmodium falciparum in southeastern Iran

\begin{tabular}{|c|c|c|c|c|}
\hline Gene & Codon/Mutation & Chabahar & Sarbaz & Total \\
\hline & & $n=152$ & $n=54$ & $n=206$ \\
\hline$p f c r t+p f m d r I$ & $76 T+86 Y$ & $63(41.4 \%)$ & $16(29.6 \%)$ & 79 (38.3\%) \\
\hline Pfdhfr & $59 R+108 N$ & $150(98.7 \%)$ & $53(98 \%)$ & $203(98.5 \%)$ \\
\hline Pfdhfr & $5 I I+59 R+108 N$ & I $(0.77 \%)$ & I (1.96\%) & $2(1.1 \%)$ \\
\hline Pfdhfr + pfdhps & $59 R+108 N+437 G$ & $24(15.8 \%)$ & $18(35.3 \%)$ & $42(20.4 \%)$ \\
\hline $\begin{aligned} \text { pfcrt } & \text { pfmdr I + pfdhfr } \\
& + \text { pfdhps }\end{aligned}$ & $\begin{array}{c}76 T+86 Y+59 R+ \\
108 N+437 G\end{array}$ & $13(8.55 \%)$ & $9(17.6 \%)$ & $22(10.7 \%)$ \\
\hline
\end{tabular}

ated with CQ resistance and has the potential as a molecular predictor for CQ therapeutic treatment failure in Iran.

Furthermore, in vivo and in vitro study of clinical failures with SP reported since $1993[9,34]$, but in vivo resistance of $P$. falciparum to SP is not yet common in malarious endemic area with a high level of CQ resistance in Iran. To investigate and complete molecular surveillance on SP efficacy in Iran, 206 collected $P$. falciparum isolates during 2003 to October 2005, have been analyzed. At the time that the present study initiated, SP was used for CQ treatment failures, as treatment failure of SP was not frequent in the region, at the end of this study, the CDMC and MHME revised the standard treatment recommendations for uncomplicated malaria to CQ plus SP as first line and Co-Artem, as second line anti malarial drugs, respectively.

All 206 P. falciparum isolates examined in this study carry pfdhfr $108 \mathrm{~N}$ mutation (100\%) with no evidence of clinical failure of SP in patients. Although it has been postulated that $p f d h f r 108 \mathrm{~N}$ mutation might be a good marker of clinical SP resistance [35], but high prevalence of this mutation in areas with low clinical failure to SP may be associated with prior primaquine exposure [36] and this could explain the fixed prevalence of this mutation among our isolates. Further study is needed to clarify the association of primaquine exposure and pfdhfr $108 \mathrm{~N}$ mutation rates.

It was also found that polymorphism in the pfdhps gene were found less frequent in $P$. falciparum population in Iran. The only mutation detected in P. falciparum isolates from both study areas was pfdhps 437G. This mutation was rather more prevalent in Sarbaz (33\%), in border area with Pakistan, while its prevalence in Chabahar isolates is almost half (17\%), indicating that this mutant parasites might have been spread through the Indian subcontinent to Pakistan and further to Iran. However, this observation remains to be clarified by further study on Pakistani $P$. falciparum isolates. Also in comparison with our previous work [37], the results of this study showed that the rate of pfdhps $437 \mathrm{G}$ mutation has been increased from $17 \%$ mixed form to $21.3 \%$ pure form in Iran. Similarly, Heidari and co-workers [34] reported the increase of this mutation in Sistan and Baluchistan province.

Chabahar and Sarbaz isolates showed similar mutations pattern and combination at pfahfr 51I, 59R, $108 \mathrm{~N}$ and pfdhps $437 \mathrm{G}$ positions, but with varied mutation prevalence. The haplotype 59R, 108N (pfdhfr), 437G (pfdhps) was more prevalent in Sarbaz (35.3\%) than Chabahar $(15.8 \%)$ districts. It is worth to note that, $27.4 \%$ of Sarbaz isolates with these three mutations isolated from patients who either had trip to or came from Pakistan two-three weeks prior to blood sampling. Hence to control of the disease, it should be kept in our mind the possibility of the spread of these alleles from neighbouring countries to malaria settings in Iran. Therefore, the predominant $p f d h f r$ haplotype in Iran seems to be N51,59R,108N rather than $51 \mathrm{I}, 59 \mathrm{R}, 108 \mathrm{~N}$. Low prevalence of triple mutation in examined isolates in this study was similar with finding from India [38,39], Sri Lanka [40] and Papua New Guinea [41], however was different with Vietnam [16,42]; Malaysian [43], Gaboni [44] and Brazilian [45] isolates, where the predominant haplotype was $51 \mathrm{I}, 59 \mathrm{R}, 108 \mathrm{~N}$. This may suggested that the $p f d h f r$ allele has evolved independently due to drug pressure in geographically isolates regions of the world. Regarding CQ resistant $P$. falciparum, it was believed that resistant parasites emerged in South East Asia and then spread to Africa via the Indian subcontinent; however the results of recent works $[46,47]$ was contrary to such hypothesis. In case of SP resistant parasites, if the same hypothesis was true, the data from present study is not supporting a presumed spread of resistant parasites from South East Asia, and multiple geographic foci for the origin of both CQ and SP resistance mutations might be postulated. The high prevalence of double mutations at codon $59 \mathrm{R} / 108 \mathrm{~N}$ rather than $51 \mathrm{I} / 108 \mathrm{~N}$ in our parasite isolates suggested that 51I mutation would be a good molecular marker for the triple mutant and indicating failure to pyrimethamine in Iran and also Indian subcontinent. In addition, these two mutations with the mutation at $437 \mathrm{G}$ position in $d h p s$ indicate that the $P$. falciparum parasite populations have the potential to evolve 


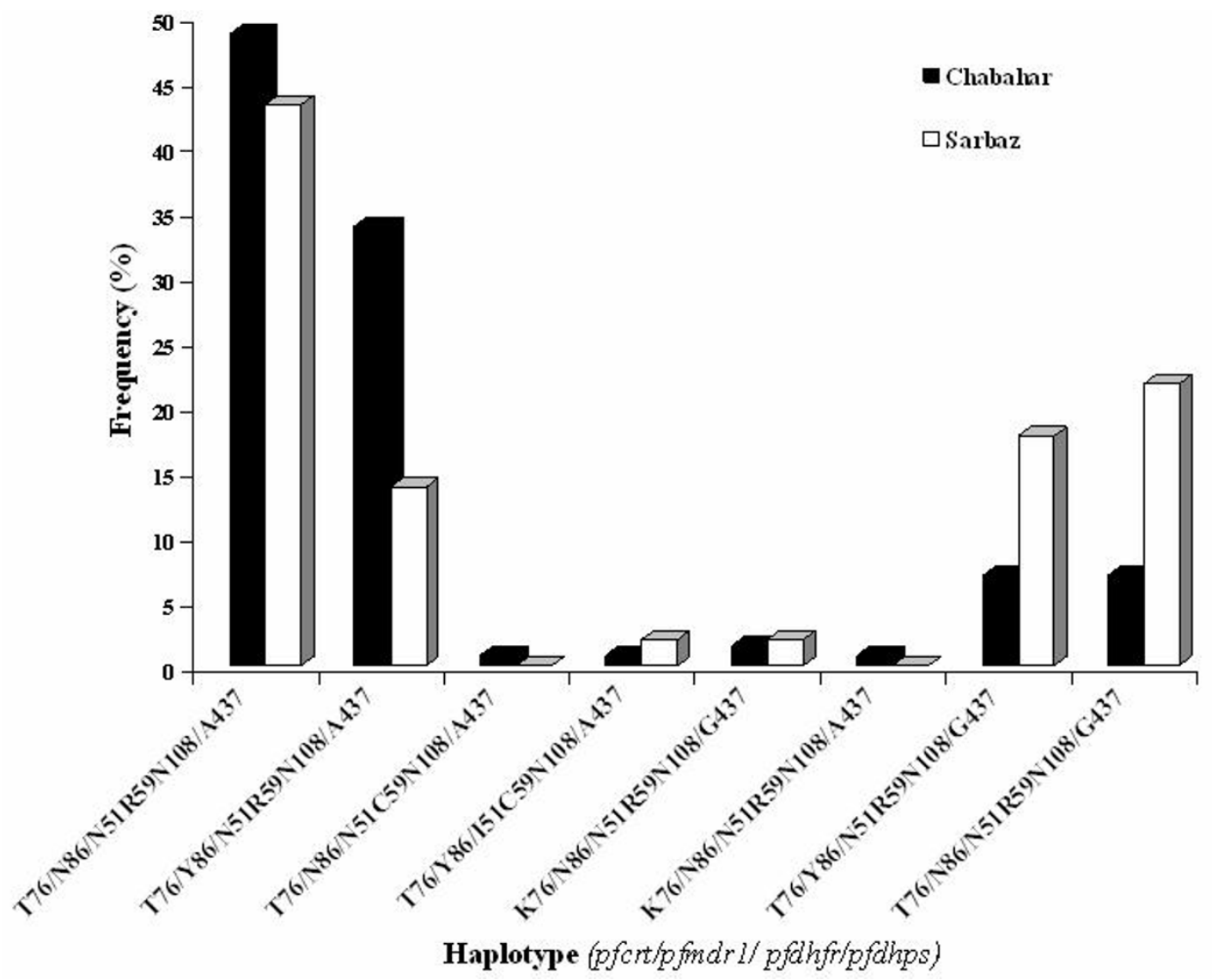

$$
\begin{aligned}
& \text { Crt / mdr1/ dhfr /dhps crt/ mdr1/ dhfr /dhps }
\end{aligned}
$$

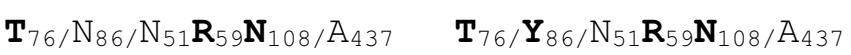

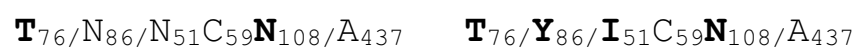

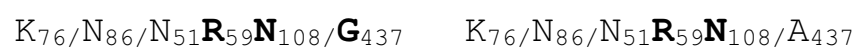

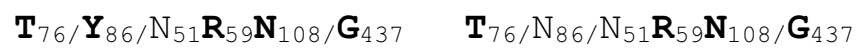

\section{Figure 2}

Frequency distribution of the combination $p f c r t / p f m d r l / p f d h f r / p f d h p s$ haplotypes obtained from 206 isolates collected in Sistan and Baluchistan of Iran. The haplotype $\mathbf{I}_{76 /} \mathbf{N}_{86} \mathbf{N}_{51} \underline{\mathbf{R}}_{59} \underline{\mathbf{N}}_{108 /} \mathrm{A}_{437}$ was the most prevalent among Chabahar (48\%) and Sarbaz (43\%) P. falciparum isolates. Mutated amino acids are boldfaced.

into $d h f r / d h p s$ quintuple mutant polymorphism in near future, therefore, monitoring of the status of dhps alleles could be a high priority as a predictor of developing clinical resistance to sulphadoxine in this region.

\section{Conclusion}

In conclusion, the present results demonstrated the low progressing rate in SNPs frequencies in both $p f d h f r$ and pfdhps genes since 2003 to 2005, more likely due to not having easily access to SP as antimalarial drug for self treatment by patients in these malaria-endemic areas of Iran. In addition, finding the fixed level of CQ resistance polymorphisms ( $p f c r t 76 \mathrm{~T}$ ) in our studied isolates suggested that the CQ must be withdrawn from the current treatment strategy in Iran. However, since October 2005, based on evidence of high rates of chloroquine treatment failure, Iran revised its national policy for treatment of malaria and SP combination therapy with CQ have 
replaced the $\mathrm{CQ} / \mathrm{P}$ as first line antimalarial drug. Thus now with more availability of SP there is possibility of increasing resistance to SP from moderate to high and its rapid spread in this particular malaria setting. Therefore, although the results of this study suggested that SP may remain the treatment of choice for uncomplicated malaria in Iran, but due to high rates of treatment failures to $C Q$, serious consideration must now be given to replace SP/ CQ combination therapy with SP/artemisinin as first line antimalarial drugs in near future in Iran, which has already been shown to be effective against CQ resistant isolates of $P$. falciparum.

\section{Authours' contributions}

SZ designed the study, and was responsible for supervision of laboratory work, development of the protocols, carrying out most parts of the laboratory experiments, analysis of data and writing up the paper with contribution of NDD. Also, MA was involved in laboratory work. AR coordinated for blood sampling and data processing. All authors read and approved the manuscript.

\section{Acknowledgements}

We are indebted to the patients and their families in Sistan and Baluchistan province for their willingness to parcipitate in this study. We also acknowledge with deep respect the co-operation of Center for Diseases Management and Control (CDMC), particularly Dr. M.M. Gouya, and are also grateful for the hospitality and generous collaboration of Zahedan University of Medical Sciences (Dr. M. Salehi), and the staff of the Public Health Department, Sistan and Baluchistan province, Chabahar and Sarbaz district (Dr. Mehdizadeh, Dr. Ebrahimpour, Dr. Kordi, Mr. Gorgij, Mr. Bra, Mr. Bram), for their assistance in collecting blood samples from the field. This work was supported by Iranian Ministry of Health and Medical Education and Pasteur Institute of Iran.

\section{References}

I. Greenberg AE, Ntumbanzondo M, Ntula N, Mawa L, Howell J, Davachi F: Hospital based surveillance of malaria related paediatric morbidity and mortality in Kinshasa, Zaire. Bull World Health Organ 1989, 67:189-196.

2. Trape JF, Pison G, Preziosi MP, Enel C, Desgreés du Loû A, Delaunay V, Samb B, Lagarde E, Molez JF, Simondon F: Impact of chloroquine resistance on malaria mortality. CR Acad Sci III 1998, $321(8): 689-697$.

3. Chulay JD, Watkins WM, Sixsmith DG: Synergistic antimalarial activity of pyrimethamine and sulfadoxine against Plasmodiumfalciparum in vitro. Am / Trop Med Hyg 1984, 33:325-330.

4. Alecrim WD, Dourado H, Alecrim MG, Passos LF, Wanssa E, Albuquerque $B$ : In vivo resistance of Plasmodium falciparum to the combination of sulfadoxine and pyrimethamine, at RIII level in Amazons, Brazil. Rev Inst Med Trop Sao Paulo 1982, 24:52-53.

5. Hurwitz ES, Johnson D, Campbell CC: Resistance of Plasmodium falciparum malaria to sulfadoxine-pyrimethamine (Fansidar) in a refugee camp in Thailand. Lancet 1981, 16:1068-1070.

6. Kilimali VAEB, Mkfuya AR: In vivo assessment ofthe sensitivity of Plasmodium falciparum tosulphadoxine/pyrimethamine combinations (Fansidar) in six locationsin Tanzania where chloroquine-resistant $\boldsymbol{P}$. falciparum hasbeen detected. Trans $R$ Soc Trop Med Hyg 1985, 79:482-483.

7. Edrissian GH, Shahabi S, Pishva E, Hajseyed-Javadi J, Khaleghian B, Ghorbani M, Emadi AM, Afshar A, Saghari H: Imported cases of chloroquine-resistant falciparum malaria in Iran. Bull Soc Path Exot 1986, 79:217-221.
8. Raeisi A, Ringwald P, Safa O, Shahbazi A, Ranjbar M, Keshavarze $H$, Nateghpour M, Faraji L: Monitoring of the therapeutic efficacy of chloroquine for the treatment of uncomplicated, Plasmodium falciparum malaria in Iran. Ann Trop Med Parasitol 2006, 100:1 I-16.

9. Edrissian GH, Afshar A, Sayedzadeh A, Mohsseni GH, Satvat MT: Assessment of the response in vivo and invitro of Plasmodium falciparum to sulphadoxine-pyrimethamine in the malarious areas of Iran. J Trop Med Hyg 1993, 96:237-240.

10. Fidock DA, Nomura T, Talley AK, Cooper RA, Dzekunov SM, Ferdig MT, Ursos LM, Sidhu AB, Naude B, Deitsch KW, Su XZ, Wootton JC, Roepe PD, Wellems TE: Mutations in the $P$. falciparum digestive vacuole transmembrane protein PfCRT and evidence for their role in chloroquine resistance. Mol Cell 2000, 6:86 I-87I.

II. Djimde A, Doumbo OK, Cortese JF, Kayentao K, Doumbo S, Diourte Y, Dicko A, Su XZ, Nomura T, Fidock DA, Wellems TE, Plowe CV: A molecular marker for chloroquine- resistant falciparum malaria. N Engl J Med 200I, 344:257-263.

12. Sidhu $A B$, Verdier-Pinard D, Fidock DA: Chloroquineresistance in Plasmodium falciparum malaria parasites conferred by pfcrt mutations. Science 2002, 298:210-2/3.

13. Djimde A, Doumbo OK, Steketee RW, Plowe CV: Application of a molecular marker for surveillance of chloroquine-resistant falciparum malaria. Lancet 200I, 358:890-89I.

14. Sanchez C, Lanzer M: Changing ideas on chloroquine in Plasmodium falciparum. Curr Opin Infect Dis 2000, 13:653-658.

15. Peterson DS, Walliker D, Wellems TE: Evidence that a point mutation in dihydrofolate reductase-thymidylate synthase confersresistance to pyrimethamine in falciparum malaria. Proc Nat Acad Sci USA 1988, 85:9| I4-9II 8.

16. Wang P, Lee CS, Bayoumi R, Djimde A, Doumbo O, Swedberg G, Das LD, Mshinda H, Tanner M, Watkins WM, Sims PFG, Hyde JE: Resistance to antifolate in Plasmodium falciparum monitored by sequence analysis of dihydropteroate synthetase and dihydrofolate reductase alleles in a large number of field samples of diverse origin. Mol Biochem Parasitol 1997, 89:161-177.

17. Reed MB, Saliba KJ, Caruana SR, Kirk K, Cowman AF: Pgh I modulates sensitivity and resistance to multiple antimalarials in Plasmodium falciparum. Nature 2000, 403:906-909.

18. Peterson DS, Milhous WK, Wellems TE: Molecular basis of differential resistance to cycloguanil and pyrimethamine in Plasmodium falciparum malaria. Proc Natl Acad Sci USA 1990, 87:3018-3022.

19. Khalil I, Ronn AM, Alifrangis M, Gabar HA, Satti GM, Bygbjerg IC: Dihydrofolate reductase and dihydropteroate synthase genotypes associated with in vitro resistance of Plasmodium falciparum to pyrimethamine, trimethoprim, sulfadoxine and sulfamethoxazole. Am J Trop Med Hyg 2003, 68:586-589.

20. Kublin JG, Dzinjalamala FK, Kamwendo DD, Malkin EM, Cortese JF, Martino LM, Mukadam RA, Rogerson SJ, Lescano AG, Molyneux ME, Winstanley PA, Chimpeni P, Taylor TE, Plowe CV: Molecular markers for failure of sulfadoxine-pyrimethamine and chlorproguanil-dapsone treatment of Plasmodium falciparum malaria. J Infect Dis 2002, 185:380-388.

21. Triglia TJ, Menting JG, Wilson C, Cowman AF: Mutations in dihydropteroate synthetase are responsible for sulfone and sulfonamide resistance in Plasmodium falciparum. Proc Natl Acad Sci USA 1997, 94: 13944-13949.

22. Talisuna AO, Nalunkuma-Kazibwe A, Langi P, Mutabingwa TK, Watkins WW, Marck EV, Egwang TG, D'Alessandro U: Two mutations in dihydrofolate reductase combined with one in the dihydropteroate synthase gene predict sulphadoxine-pyrimethamine parasitological failure in Ugandan children with uncomplicated falciparum malaria. Infect Genet Evol 2004, 4:321-327.

23. Talisuna AO, Langi $P$, Mutabingwa TK, Watkins $W$, Van Marck E, Egwang TG, D'Alessandro U: Population-based validation of dihydrofolate reductase gene mutations for the prediction of sulfadoxine-pyrimethamine resistance in Uganda. Trans $R$ Soc Trop Med Hyg 2003, 97:338-342.

24. Nzila AM, Mberu EK, Sulo J: Towards an understanding of the mechanism of pyrimethamine-sulfadoxine resistance in Plasmodium falciparum: genotyping of dihydrofolate reductase and dihydropteroate synthase of Kenyan parasites. Antimicrob Agents Chemother 2000, 44:991-996. 
25. Nzila AM, Nduati E, Mberu EK, Hopkins SC, Monks SA, Winstanley PA, Watkins WM: Molecular evidence of greater selective pressure for drug resistance exerted by the long acting antifolatepyrimethamine/sulfadoxine compared with the shorter-actingchlorproguanil/dapsone on Kenyan Plasmodium falciparum. J Infect Dis 2000, I 81:2023-2028.

26. Mutabingwa $\mathrm{T}, \mathrm{Nzila} \mathrm{A}$, Mberu E: Chlorproguanil-dapsone for treatment of drug-resistant falciparum malaria in Tanzania. Lancet 200I, 358: I2I8-I223.

27. Basco LK, Tahar R, Ringwald $P$ : Molecular basis of in vivo resistance to sulfadoxine-pyrimethamine in Africa adult patients infected with Plasmodium falciparum malaria parasites. Antimicrob Agents Chemother 1998, 42:181 I-1814.

28. Plowe CV: Monitoring antimalarial drug resistance: making the most of the tools at hand. J Exp Biol 2003, 206:3745-3752.

29. Djimde A, Dolo A, Ouattara A, Diakite S, Plowe CV, Doumbo OK: Molecular diagnosis of resistance to antimalarial drugs during epidemics and in war zones. J Infect Dis 2004, 1 90:853-855.

30. Snounou G, Viriyakosol S, Zhu XP, Jarra W, Pinheiro L, do Rosario VE, Thaithong S, Brown KN: High sensitivity of detection of human malaria parasites by the use of nested polymerase chain reaction. Mol Biochem Parasitol 1993, 61:315-320.

31. Duraisingh MT, Curtis J, Warhust DC: Plasmodium falciparum detection of polymorphisms in the dihydrofolate reductase and dihydropteroate synthetase genes by PCR and restriction digestion. Exp Parasitol 1998, 89: |-8.

32. Duraisingh MT, Jones P, Sambou I, von Seidlein L, Pinder M, Warhurst DC: The tyrosine-86 allele of the pfmdrl gene of Plasmodium falciparum is associated with increased sensitivity to the antimalarials mefloquine and artemisinin. Mol Biochem Parasitol 2000, 108:13-23.

33. Edrissian GH, Shahabi S: Preliminary study of the response of Plasmodium falciparum to chloroquine in Sistan and Baluchistan province of Iran. Trans $R$ Soc Trop Med Hyg 1985, 79:563-564

34. Heidari A, Dittrich S, Jelink T, Kheirandish A, Banihashemi K, Keshavarz $\mathrm{H}$ : Genotypes and in vivo resistance of Plasmodium falciparum isolates in an endemic region of Iran. Parasitol Res 2007, 1 00:589-592.

35. Peterson DS, Di SS, Povoa M, Calvosa VS, Do RV, Wellems TE: Prevalence of the dihydrofolate reductase Asn-108 mutation as the basis for pyrimethamine-resistant falciparum malaria in the Brazilian Amazon. Am J Trop Med Hyg 199I, 45:492-497.

36. Gasey GJ, Ginny M, Uranoli M, Mueller I, Reeder JC, Genton B, Cowman AF: Molecular analysis of Plasmodium falciparum from drug treatment failure patients in Papua New Guinea. Am J Trop Med Hyg 2004, 70:25I-255.

37. Zakeri S, Gil JP, Bereckzy S, Djadid ND, Bjorkman A: High prevalence of double Plasmodium falciparum dhfr mutations at codons 108 and 59 in the Sistan-Baluchistan province, Iran. J Infect Dis 2003, 187:1828-1829.

38. Ahmed A, Bararia D, Vinayak S, Yameen M, Biswas S, Dev V, Kumar A, Ansari MA, Sharma YD: Plasmodium falciparum isolates in India exhibit a progressive increase in mutations associated with Sulfadoxine-Pyrimethamine resistance. Antimicrob Agents Chemother 2004, 48:879-889.

39. Biswas S, Escalante A, Chaiyaroj S, Angkasekwinai P, Lal AA: Prevalence of point mutations in the dihydrofolate reductase and dihydropteroate synthetase genes of Plasmodium falciparum isolates from India and Thailand: a molecular epidemiologic study. Trop Med Int Health 2000, 5:737-743.

40. Hapuarachchi HC, Dayanath MYD, Bandara KBAT, Abeysundara S, Abeyewickreme W, De Silva NR, Hunt SY, Sibley CH: Point mutations in the dihydrofolate reductase and dihydropteroate synthase genes of Plasmodium falciparum and resistance to sulfadoxine-pyrimethamine in Sri Lanka. Am J Trop Med Hyg 2006, 74:198-204

4I. Mita T, Kaneko A, Hwaihwanje I, Tsukahara T, Takahashi N, Osawa $\mathrm{H}$, Tanabe K, Kobayakawa T, Bjorkman A: Rapid selection of dhfr mutant allele in Plasmodium falciparum isolates after the introduction of sulfadoxine/pyrimethamine in combination with 4-aminoquinolines in Papua New Guinea. Infect Genet Evol 2006, 6:447-452.

42. Wang P, Read M, Sims PFG, Hyde JE: Sulfadoxine resistancein the human malaria parasite Plasmodium falciparum is determined by mutations in dihydropteroate synthetase and an additional factor associated with folate utilization. Mol Microbiol 1997, 23:979-86.

43. Cox-Singh J, Zakaria R, Abdullah MS, Rahman HA, Nagappan S, Singh $B$ : short report: differences in dihydrofolate reductase but not dihydropteroate synthetase alleles in Plasmodium falciparum isolates from geographically distinct areas in Malaysia. Am J Trop Med Hyg 200I, 64:28-3I.

44. Aubouy A, Jafari S, Huart V, Migot-Nabias F, Mayombo J, Durand R, Bakary M, Bras JL, Deloron P: DHFR and DHPSgenotypes of Plasmodium falciparum isolates from Gabon correlate with in vitro activity of pyrimethamine and cycloguanil, but not with sulfadoxine-pyrimethamine treatment efficacy. I Antimicrob Chemother 2003, 52:43-49.

45. Vasconcelos KF, Plowe CV, Fontes CJ, Kyle D, Wirth DF, Pereira daSilva LH, Zalis MG: Mutations in Plasmodium falciparum dihydrofolate reductase and dihydropteroate synthetase of isolates from the Amazon region of Brazil. Mem Inst Oswaldo Cruz 2000, 95:72I-728.

46. Keen J, Farcas GA, Zhong K, Yohanna S, Dunne MW, Kain KC: RealTime PCR assay for rapid detection and analysis of PfCRT haplotypes of chloroquine-resistant Plasmodium falciparum isolates from India. J Clin Microbiol 2007, 45:2889-2893.

47. Vathsala PG, Pramanik A, Dhanasekaran S, Devi CU, Pillai CR, Subbarao SK, Ghosh SK, Tiwari SN, Sathyanarayan TS, Deshpande PR, Mishra GC, Ranjit MR, Dash AP, Rangarajan PN, Padmanaban G: Widespread occurrence of the Plasmodium falciparum chloroquine resistance transporter(PFCRT) gene haplotype SVMNT in P. falciparum malaria in India. Am J Trop Med Hyg 2004, 70:256-259.
Publish with Bio Med Central and every scientist can read your work free of charge

"BioMed Central will be the most significant development for disseminating the results of biomedical research in our lifetime. "

Sir Paul Nurse, Cancer Research UK

Your research papers will be:

- available free of charge to the entire biomedical community

- peer reviewed and published immediately upon acceptance

- cited in PubMed and archived on PubMed Central

- yours - you keep the copyright

Submit your manuscript here:

http://www.biomedcentral.com/info/publishing_adv.asp 